\title{
独立性証明とその展望
}

難 波 完 爾 ${ }^{*}$

証明とか公理系について我々が一番よく知っているも のは, 例の Euclid の “幾何原本”であろう。この中に 平行線の一意性を意味する “平行線の公理”があり，こ れが他の公理から導かれるかどらかは永い間の重大な問 題であった。そして，この公理は当初からその自明性に 疑問に持たれていたといら。このことに関係しては後に N. Lobačevckii， J. Bolyi による双曲幾何学そして B. Riemann による楕円幾何学の発見へと続いている。

また, D. Hilbert は Euclid 幾何学の完全な公理系を 与えて平行線公理が他の公理から独立であることを示し ている。そして A. Cayley, F. Klein, H. Poincaré 等は Euclid 空間の中に非 Euclid 空間の model を作って, Euclid 幾何学の無矛盾性から非 Euclid 幾何学の無矛盾 性が碚かれることを示している。また A. Einstein の相 対性理論によれば我々のいる空間は非 Euclid 的である と考党られている。

さて，ここで述べょうと思うのは，我々の住む空間の 方ではなくて，我々の用いている論理とか“もの〉集り” に関係する概念について，その記述の可能性や能力につ いてである。

素朴な意味で”もの〉集り“が考えられたのは言葉と か文字が用いられ始めたと同じ位の昔にさかのぼるであ ろらが，自然数の全体とか実数の全体等の概念がはっき り認識されそして“集合”の概念がそれらの色々の性質 の記述に有効に用いられるようになったのは比較的新し いことで，例光ば自然数の全体と実数の全体が 1 対 1 に 対応できないことなど G. Cantorによって証明されたの は，ほんの 1 世紀と少し前の話である。

このような時にすでに G. Cantorによって二つの身近 な無限基数，すなわち自然数と実数のそれの間に他の無 限基数があるかどらか問題にされていた。すなわち，実 数の集合で自然数の全体を含むものは必ず実数の全体か 自然数の全体と 1 対 1 に対応できるであろらという“連 続体仮説”を程出し, 彼自身一生その解決に努力したの であるがそれを果すことはできなかったのである。

また, 彼自身, 整列順序を研究し順序数の理論を作り

* 東京大学教養学部
上げて, 素朴に順序数の全体を考えると, それが再び順 序数の性格を有することを発見し，順序数であれば矛盾 することを導いた。そして，B. Russel は，集合論の一 番基本的概念である“属する”といら述語に関係して, 自分自身を要素として含まない集合の全体

$$
\{x \mid x \notin x\}
$$

は，集合であれば，再びこの性質をもち，定義によって 自分自身を要素として含まねばならないという，いわゆ る Russel の paradax を得ている。このようにして, “順 序数の全体”とか“自分自身の要素でない集合全体”を 再び集合と考光ることによって導かれる矛盾をさけてこ れらの“もの”惟合と区別するような公理体系が考学 られるに至ったわけである。その中で比較的自然なるの としてょく用いられているものはZermelo-Fraenkelの体 系と Gödel-Bernays の体系であるが，ここではZermeloFraenkel の公理系を記して扰こう。

\section{ZF の公理系}

以下に Zermelo-Fraenkel の集合論 ZF の公理系およ びそれによって定義される集合について簡単に記してお こう。

1 Extensionality (外延性)

$$
\forall x(x \in a \equiv x \in b) \equiv a=b
$$

2 Pair (対集合) $\{b, c\}$

$$
\exists a \forall x(x \in a \equiv x=b \vee x=c)
$$

3 Sum (和集合) $\cup b$

$$
\exists a \forall x(x \in a \equiv \exists y \in b(x \in y))
$$

4 Power (幅集合) $p(b)$

$$
\exists a \forall x(x \in a \equiv \forall y \in x(y \in b))
$$

5 Empty set (空集合) $\phi, 0$

$$
\exists a \forall x(x \notin a)
$$

6 Infinity（無限集合）

$$
\exists a(0 \in a \wedge \forall x \in a(x+1 \in a))
$$

ここに $x+1=x \cup\{x\}, x \cup y=\cup\{x, y\}$

7 Comprehinsion（部分集合） $\{x \in b: P(x)\}$

$\exists a \forall x(x \in a \equiv x \in b \wedge P(y))$

8 Replacement（置換公理） 
$\forall x \in a \exists y P(x, y) \equiv \exists y \forall x \in a \exists z \in y P(x, z)$

9 Foundation（基礎公理）

$$
\exists x P(x) \rightarrow \exists x(P(x) \wedge \forall y \in x\urcorner P(y))
$$

またはその対偶である

$9^{\prime}$ Induction (㷌納法)

$$
\forall x(\forall y \in x P(y) \rightarrow P(x)) \rightarrow \forall x P(x)
$$

10 Choice（選択公理）

$$
\forall x \in a \exists y P(x, y) \equiv \exists y \forall x \in a P(x, y(z))
$$

これらの公理について通常 $1 \sim 9$ を $\mathrm{ZF}$, それに axiom of choice を加えて ZFC と呼んでいる。また，例壳ば pairの公理は他の公理から導かれるが，これを除くと公 理系の記述の単純さを失らかも知れないので入れておい た。

さて, これらの公理の内容がぞの程度 $\forall x \in a, \exists x \in a$ のような制限された束縛記号を用いて記述されるかは, 形式の上のみならず，その概念の“確定性”と関係して 重要な意味を有しているのでここにそれを記しておく， そしてすべての束縛記号が制限された論理式を bounded formula と呼ぶ, これらの概念とその拡張は K. Gödel が “absolute”と呼んだものに相当している。

Extinsconality に対しては

$$
\forall x \in a(x \in b) \wedge \forall x \in b(x \in a) \equiv a=b
$$

Pair に対しては 百 $a$ を除いた部分は,

$$
\forall x \in a(x=b \vee x=c) \wedge b \in a \wedge c \in a
$$

Sum に対しても,

$$
\forall x \in a \exists y \in b(x \in y) \wedge A y \in b \forall x \in y(x \in a)
$$

でありいずれも bounded formula であるが

Power に対しては，その意味を素朴に記せば

$$
\forall x \in a \forall y \in x(y \in b) \wedge \forall x H y \in x(y \in b \rightarrow x \in a)
$$

であって，後半の $\forall x$ は制限されていない束縛変数であ るが，このことは集合論の model の概念と巾集合の概念 がいかにかかわっているかを示す重要な点であって, こ の公理は bounded formula としては表現できないこと が，例えば，P.J. Cohen の結果等によって解っている。

Empty set については, もちろん

$$
\text { ᄀ马 } x \in a
$$

Infinity についても

$$
\begin{gathered}
0 \in a \wedge \forall x \in a \exists y \in a(x \in y \wedge \forall z \in x(z \in y) \\
\wedge \forall z \in y(z=x \vee z \in x))
\end{gathered}
$$

Comprehinsion に対しても

$$
\forall x \in a(x \in b \wedge P(x)) \wedge \forall x \in b(P(x) \rightarrow x \in a)
$$

であって $P(x)$ が bounded なら bounded である。

また， Replacement と Axion of choice は制限された 束縛記号と制限されてない束縛記号の交換可能性につい
ての性質であって，制限されていない束縛記号の種類と か順序がはっきり意味を有することを述べている。

さて，無限公理は内容的には“自然数の全体”を一つ の集合と考えるという内容的意味を有している。まず各 自然数の方は

$$
0 \quad 1=\{0\} \quad 2=\{0,1\} \quad 3=\{0,1,2\} \cdots
$$

そして, 一般に $n+1=n \cup\{n\}=\{0,1, \cdots, n\}$ によって定 められることに注意する。そうすれば

$$
0 \in a \wedge \forall x \in a(x+1 \in a)
$$

の意味するところは $\omega$ はすべての自然数を含むことであ り, “自然数の全体” “ “数学的㷌納法”によって特徵 づけられると考えるのが自然であるから，その集合を $\omega$ と記すると

$$
\omega=\{x \in a: \forall y(0 \in y \wedge \forall z \in y(z+1 \in y) \rightarrow x \in y)\}
$$

となる。

この自然数の概念を用いると, 選択公理によって depending choice (DC) と呼ばれる次の原理

$$
\begin{aligned}
\exists x P(x) & \wedge \forall x \exists y R(x, y) \rightarrow \exists x(P(x(0)) \\
& \wedge \forall n \in \omega R(x(n), x(n+1)))
\end{aligned}
$$

を導くことができる。そして解析学や代数学等で用いら れる “構成的”な証明法の多くはこのような範囲内にあ ることが知られているが，例えば, Lebesgue 非可測集 合の存在とか Hahn-Banach の拡張定理等は DC の範围 外にあることが知られている。

ここで基礎の公理についてであるが，その否定は，あ る性質 $P(x)$ について

$$
\operatorname{ExP}(x) \wedge \forall x\} y \in x(P(x) \rightarrow P(y))
$$

であるから，特に

$$
\exists x \forall n \in \omega(x(n+1) \in x(n))
$$

であるが，逆に $\forall n \in \omega(a(n+1) \in a(n))$ ならば

$$
P(x \equiv E n \in \omega(x=a(n))
$$

とすれば，基礎の公理の否定を得るから，基礎の公理は

“無限下降列の存在しない”こと

$$
\forall x E n \in \omega(x(n+1) \notin x(n))
$$

表現することもできる。

選択公理は他の公理と比較して特別な性質を有してい る。それは “函数”の概念を直接的な形で含んでいるこ と, 形式の上でも単純であること，そして非常に多くの 性質と同等であることである。ここにそれらの性質につ いて記しておこう。

(a) 整列可能定理 “すべての集合に整列順序を導入することができる”

(b) Zorn の補題 “すべての㷌納的順序集合は極元を有する” 
(c) 空でない集合の直積は空でない

(d) 分配法則

$$
\forall x \in a(f(x) \neq \phi) \rightarrow \prod_{x \in a} f(x) \neq \phi
$$

$$
\bigcap_{x \equiv a} \underset{y \in f(x)}{\cup} g(x, y)=\underset{\substack{t \in \prod_{x \in a} f(x) \\ x \in a}}{\bigcap} \underset{x \in a}{ } g(x, t(x))
$$

(e) 濃度の比較可能性

$$
\overline{\bar{a}} \leq \overline{\bar{b}} \vee \overline{\bar{b}} \leq \overline{\bar{a}}
$$

(f) surjection の右逆元の存在

$$
f: a \stackrel{\text { onto }}{\longrightarrow} b \longrightarrow E g\left(f \circ g=1_{b}\right)
$$

実数の集合とか函数についての性質の中には選択公理 なしでは証明できないものも多い。例えば，距離空間で の函数の連続性に関する $\varepsilon-\delta$ 式定義

$\forall \varepsilon>0\} \delta>0 V y(|x-y|<\delta \rightarrow|f(x)-f(y)|<\varepsilon)$ と点列による定義

$$
\lim _{n, \infty} f\left(p_{n}\right)=f\left(\lim _{n \rightarrow \infty} p_{n}\right)
$$

の同等性等は ZF のみでは証明できない。すなわち，例 えば次の二性質

$$
\begin{gathered}
\forall n \in \omega A y\left(|x-y|<\frac{1}{n} \wedge|f(x)-f(y)| \geqslant \varepsilon\right), \\
\text { By } \forall n \in \omega\left(|x-y(n)|<\frac{1}{n}\right. \\
\wedge \mid f(x)-f(y(n) \mid \geqslant \varepsilon)
\end{gathered}
$$

の同值性を ZF のみからは臫くことができないのであ る。もちろん例えば実数の全体の上に定義可能な整列順 序があれば上の同值性はすぐに証明できるから，実数の 全体の整列可能性等む ZF では証明不可能である。この ことは P.J. Cohen の1963年の結果の一つである。

さて，ここで用いられた countable choice, すなわち $\forall x \in \omega \exists y P(x, y) \equiv \exists y \forall x \in \omega P(x, y(x))$

は DC から溥かれることは次のようである。 今, 次の式

$$
\begin{aligned}
& P(x) \equiv \operatorname{dom}(x)=1 \wedge P(0, x(0)) \\
& R(x, y) \equiv {[\operatorname{dom}(x)+1=\operatorname{dom}(y) \in \omega} \\
& \wedge \forall z \in \operatorname{dom}(x)(x(z)=y(z)) \\
&\wedge \forall z \in \operatorname{dom}(x) P(z, x(z))] \rightarrow \\
& \forall z \in \operatorname{dom}(y) P(z, y(z))
\end{aligned}
$$

によって $P(x), R(x, y)$ を定義すれば

$\forall x \in \omega \exists y P(x, y) \rightarrow \exists x P(x) \wedge \forall x \exists y R(x, y)$

であるから DC によって

$$
\exists y(P(y(0))) \wedge \forall x \in \omega R(y(z), y(x+1)))
$$

である。そこで $f(n)=y(n+1)(n)$ とすると

$$
\forall x \in \omega P(n, f(x))
$$

\section{を得る。}

また, Lebesgue 非可測集合の存在は G. Vitali による
のであるが，この時用いられた選択公理は可算集合の非 可算個の組から同時に代表元を選ぶのであるから，例え ば非可算集合の可算個の組から代表元を選 ぶ countable choice とは本質的に異なるのである。

これに関係しては R. Solovay の結果が知られている。 すなわち ZF と inaccessible cardinal,

$$
c f(x)=\kappa, \forall \alpha<\kappa\left(2^{\alpha}<\kappa\right)
$$

なる基数の存在を仮定すると，ZF の model でその中で は

“実数の有界集合はすべて Lebesgue 可測”

$$
\text { “dependent choice" }
$$

の両方が成立することが証明されている。これより例え ば dependent choice DC と ZF の下では Lebegue 非可 測な集合の存在は証明できないことになる。

さて，ここでBanach-Tarskiによる奇妙な結果につい てふれておこう。そのために分割合同の概念を定義して おく。すなわち，二つの集合を対応するものが各々合同 な有限個の部分に分割できるとき，この二つの集合は分 割合同と呼ぶのである。例えば，面積の等しい多角形は 常に分割合同であることはよく知られている。ところで 上記の Banach-Tarski の結果は，選択公理を用いると， 3 次元 Euclid 空間では “一つの単位球が二つの単位球 と分割合同”であって，さらに内部を有する有界な集合 は常に分割合同という奇妙な結果になるのである。した がって Lebesgue 測度は保たれないわけであるから，分 割合同の証明に用いられた成分の少くとも一つは非可測 でなくてはならない。ここで用いられる選択公理は実数 の整列可能性から導かれる程度の強さである。しかし， 例えば直線上の内部を有する有界図形が常に分割合同か ぞらかについては知らない。

また，W. Sierpinski によるという次の結果も面白い。 すなわち

“平面上の集合で任意の直線と常に二点のみで交わる ものが存在する”

といらのであるが，このような初等的な罒形の存在は興 味がある。

\section{2. 無矛盾性と独立性}

連続体仮説と選択公理に対しては W. Sierpinskiによ って次のような結果が知られている。すなわち

“一般連続体仮説から選択公理が導かれる”

といらものである。ここに一般連続体仮説 $(\mathrm{GCH})$ とは 任意の無限集合に対して

$$
\overline{\bar{a}} \leq \overline{\bar{b}}, \overline{\bar{b}} \leq 2{ }^{=} \rightarrow \overline{\bar{b}} \leq \overline{\bar{a}}, \overline{\overline{2}}^{a} \leq \overline{\bar{b}}
$$


が成立するということである。もちろん，選択公理が成 立すれば，連続体仮説は無限の順序数の中のいわゆる始 数 ぶを用いて

$$
\forall \alpha\left(2^{\aleph \alpha}=\aleph_{\alpha+1}\right)
$$

のように記することができる。

この証明には，例えば，順序対を

$$
(x, y)=\{\{x\},\{x, y\}\}
$$

で定義すると，集合 $a$ 上の整列順序の同值類のなす整列 集合は $p^{4}(a)$ に含まれることが用いられている。

また，K. Gödel は構成的集合の概念を定義してその 全体が集合論 ZFC の公理をすべて満足しさらにその中 で一般連続体仮説が成立することを示した。

この方法は Euclid 空間の中に非 Euclid 空間を構成 したことに対比できるであろう。そして，このような方 法を内部 model による方法と呼んでいる。P.J. Cohen の方法や R. Solovay, D. Scott のブール代数值の集合論 の model についてもこの延長線に属するものである。

K. Gödel の結果は集合の全体 V(Vollraum) は構成 的集合の全体 $\mathrm{L}$ と一致するという性質を $\mathrm{V}=\mathrm{L}$ と記せば $\mathrm{V}=\mathrm{L} \rightarrow \mathrm{GCH}$

ということである。また，選択公理を $\mathrm{AC}$ と記せばW． Sierpinski の結果と合せて

$$
\mathrm{V}=\mathrm{L} \rightarrow \mathrm{GCH} \rightarrow \mathrm{AC}
$$

を得るわけであるが，逆方向は成立しないことは P.J.

Cohen によって証明された。すなわち

$$
\mathrm{AC} \rightarrow \mathrm{GCH} \rightarrow \mathrm{V}=\mathrm{L}
$$

であるというのである。

さて, 構成的集合の全体 Lの上には定義可能な整列順 序があり，乙たがって選択公理が導かれるのであるが， Gödel はこのことを, 論理体系の code (Gödel number) が記号列として自然に整列するように選べること，およ び，順序数の整列性を用いて示している。すなわち，順 序数に関する㷌納法で導入される構成的集合を最初に導 入された段階の順序数, 次にその定義式の code といら 順で整列するのである。

したがって，構成可能性 $\mathrm{V}=\mathrm{L}$ の下では

“集合全体に定義可能な整列順序が入る”

といら非常に強力な性質が得られ，これは

“任意の集合が整列可能である”

といらことょり強いものである。このことはやはり P.J.

Cohen によって示されたことである。

さて，連続体仮説の方であるが，この証明に用いられ た基本的概念は，いわゆる Skolem の函数であろう。す なわち

$$
\begin{gathered}
\forall x_{1} \in a \cdots \forall n_{n} \in a\left(\exists x A\left(x, x_{1}, \cdots, x_{n}\right)\right. \\
\left.\equiv A\left(f\left(x_{1}, \cdots, x_{n}\right), x_{1}, \cdots, x_{n}\right)\right)
\end{gathered}
$$

なる四数 $f$ であって，このような函数が存在するという のが選択公理の意味でもある。

そして，集合 $a$ が，例えば，論理式 $A\left(x, x_{1}, \cdots, x_{n}\right)$

の Skolem 函数について閉じていれば,

$$
\begin{aligned}
& \forall x_{1} \in a \cdots \forall x_{n} \in a\left(\exists x A\left(x, x_{1}, \cdots, x_{n}\right)\right. \\
& \left.\quad \equiv \exists x \in a A\left(x, x_{1}, \cdots, x_{n}\right)\right)
\end{aligned}
$$

であるが，このような点に着目して，構成的集合の全体 を定義する論理式のすべての部分論理式の Skolem 函数 による閉包を考劣るのである。順序数 $\alpha$ までの段階で尊 入された構成的集合の全体を $M_{\alpha}$ とすれば， $\alpha か ゙$ 無限で あれば

$$
\overline{\overline{M_{\alpha}}}=\overline{\bar{\alpha}}
$$

であるという性質がある。そして構成的集合 $\mathrm{u} か ゙ \mathrm{u} \subset M_{\alpha}$ とすると $M_{\alpha} \cup\{u\}$ の上のような Skolem 函数による閉

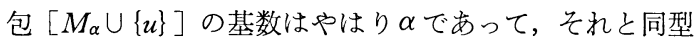
を集合は $M_{\beta}$ の形でなくてはならないとこが示され， $M_{\alpha}$ が transitive, すなわち

$$
\forall x \in M_{\alpha} \forall y \in x\left(y \in M_{\alpha}\right)
$$

であることから $u \in M_{\beta}$ が得られる，また $\beta=\alpha$ である ことから， $\alpha^{+}$を $\alpha$ 次の基数とすれば,

$$
u \subset M_{\alpha} \rightarrow u \in M_{\alpha}+
$$

が得られることになり，一般連続体仮説が成立するので ある。これが Gödel の証明の論旨である。

これらの方法は，例えば Skolem の定理，すなわち

“可算個の公理から成る体系が無矛盾ならば，その体 系の可算な model が存在する”

といらことの証明に用いられたものと同様である。これ を，例えば，現在は無矛盾と考えられている集合論の公 理系 ZF に対して用いると，集合論 ZF の可算な model が得られることになるのであるが，この model の中て の実数の全体は Cantor の対角線論法によって “非可算” なはずであるが，この可算な model の一部分であるか ら “可算”でなくはならないことになり，一種の矛盾に 見える。これを Skolem の “paradox”と呼んでいるわ けであるが, model の中の “非可算” は model の中に は $\omega$ との 1 対 1 対応がないということで，その外には存 在するので “可算”となっているのであろう。またこの ことは model の外には多くの “実数”があることも意 味しているのであろう。

このことはもら歴史の方に属するのかも知れないが， このような “paradox”も言葉や見方の変化によって, 例えば“連続体仮説の無矛盾性”のような形に表現され 
るのは興味深いことである。そしてまた，その発見も最 初はしばしば“paradox”として人々の興味を引きつける のであろう。そして，このようなことは我々が，何故か 知らず，無意識に認めている原理の中にもいくらでもあ り得ることであろらし，またそのよらに指摘され，そし て実際にその立場に立ってみてはじめて“はっきり”と 見えるよらな事実もあろらと思えるのである。

無矛盾性といら概念が出て来たので, それについて語 るには K. Gödel の不完全性定理についてふれておくの が自然であろうと思ら。

例えば，自然数論や集合論の公理 ZFC のよ5に

「その公理が“はっきり”述べられるような体系が自 然数論を含久無矛盾であれば，その事実，すなわち， その“体系の無矛盾であること”はその体系の中では証 明できない」

というのである。もちろん，その体系が無矛盾であれば 偽の命題である “その体系は矛盾している”ことは証明 不可能である。その体系が矛盾していれば，例えば，

“その体系は無矛盾である”という偽の命題でも, その 定義にしたがって証明できるであろう。

話はかわるが，“おれは絶対に酔っていない”と叫ん で，友人から“酔っぱらったな”等といわれるに似てい るかも知れない。また，時には“扔れは絶対に正しい” といっているのを見ることもあるが，これにも色々な可 能性があるであろう。

上で述べた“はっきり”と述べられるということの意 味は“帰納的噪数”でその公理すべて述べることができ るといらことである。そして，その体系が理矛盾であれ ば, “その体系が無矛盾であること”は“正しい”ので あるが“証明できない”ことであり，また，その否定も 肯定も証明できない例であるといらのである。

これを例えば, 集合論 ZF について考えれば, 無限公 理によって, 自然数の全体が一つの集合であるから, 自 然数の理論はその中で展開でき, したがって, もし ZF が無矛盾であれば, “ZF の無矛盾性”はZF のみでは証 明できないここになる。我々が現在用いている数学上の 手法は，例えば “category の category” 等は別にして,大 部分 ZF の中におさまるのであるから，ZF の無矛盾性 の証明といらのはかなり困難なものであろら。我々が素 朴に考学ている “集合” の全体が ZF の model である から，ZFから矛盾など出る訳がない，“出るなら出して みろ”といら説もあるかも知孔ない。しかし, 本当であ ろらか。かといって, もちろん, 矛盾があると信じてい るわけではないが，また，矛盾がないと信じているわけ
でもない。ともあれ，あまりに“二值的”世界観の中に 感覚が “埋れて”いないであろらか，また，それを“忘 れて”いないであろらか少し気になるところである。

\section{3. 無限公理}

さて, 集合論 ZF の無矛盾性が証明できる程度の大き な集合の存在を主張する “無限公理” も色々研究されて いるのでその二，三について記しておこう。

その一つは, 正則な基数 $\boldsymbol{\aleph} \alpha$ で

$$
\forall \beta<\alpha\left(2 \boldsymbol{\aleph}_{\beta}<\boldsymbol{\aleph} \alpha\right)
$$

を満足する基数の存在である，これは到達不可能な基数 (inaccessible cardinal) と呼ばれている。例えば帰納法 で

$$
R(\alpha)=\underset{\beta<\alpha}{\mathscr{P}}(\bigcup R(\beta))
$$

とするとき，集合

$$
\underset{\beta<\aleph_{\alpha}}{\bigcup} R(\beta)
$$

が ZF の model となるよらな基数といらこともできる。 当然のことであるが，このよらな基数の存在は ZF から 証明できない。だから，もし無矛盾ならば独立でなけれ ばならない。

次のものは “measurable curdinal” 存在の公理である。 すなわち

$$
\mu: \mathscr{P}(x) \rightarrow \mathscr{P}(1)=\{0,1\}
$$

なる可算加法的測度の singleton 上で消えてしまうもの の存在である。これは Bool 代数の準同型で non-principal で可算完備なもの, 存在である。このようなもの, 最小 のものを とすると例えば，適当な条件を満足する model の存在のように, 制限されない束縛変数が马のみ の論理式については

$$
\exists x P(x) \rightarrow \exists x<\aleph_{1} P(x)
$$

である。例えば，構成的集合の全体 $L$ の中の ち, $\aleph_{1}{ }^{L}$ については $\aleph_{1}{ }^{L}<\aleph_{1}$, いいかえれば, $\aleph_{1}{ }^{L}$ は 可算である。

また， $\alpha$ は非可算基数であるといら性質のよらに，制 限されない束縛変数が $\forall$ のみの論理式については

$$
\exists x P(x) \rightarrow \exists x<\beth_{1} P(x)
$$

である。例光ば, 最小の到達不可能な基数ぶについて は $\boldsymbol{\alpha}_{\alpha}<\beth_{1}$ となることなど知られている。

この性質は現在のところ集合論の公理 ZFC と矛盾し ないと考えられているが，もちろん，無矛盾性の証明が あるわけではない。もし将来矛盾が導かれることがあれ ば，これは“無限公理”の中ではそんなに強いものでは ないこともあって, この方向の研究は大きく影響される 
であろうし，その時用いられる概念は興味深いものであ ろら。また，非常によい結果として評価されることは間 違いなかろら。

さて最後の例は “決定性公理” (axiom of determinateness，AD）と呼ばれるもので Mycielski によるもので ある。これは game の理論と関係している。例えば, 次 のような論理式

$$
\forall x_{1} \exists y_{1} \forall x_{2} \exists y_{2} A\left(x_{1}, y_{1}, x_{2}, y_{2}\right)
$$

に対して，一般には選択公理を用いて

$$
\text { 马 } y_{1} \text { 百 } y_{2} \forall x_{1} \forall x_{2} A\left(x_{1}, y_{1}\left(x_{1}\right), x_{2}, y_{2}\left(x_{1}, x_{2}\right)\right)
$$

を得るが, $\left(x_{1}, x_{2}\right)$ が先手の “手” であり, 函数列 $\left(y_{1}\right.$, $\left.y_{2}\right)$ が後手の “必勝法” と呼ばれているものである。し たがって，上の論理式の否定

$$
\urcorner \forall x_{1} \exists y_{1} \forall x_{2} \exists y_{2} A\left(x_{1}, y_{1}, x_{2}, y_{2}\right)
$$

は de Morgan の法則にしたがって

$$
\text { B } \left.x_{1} \forall y_{1} \exists x_{2} \forall y_{2}\right\urcorner A\left(x_{1}, y_{1}, x_{2}, y_{2}\right)
$$

であるが，これも選択公理より

$$
\left.\exists x_{1} \exists x_{2} \forall y_{1} \forall y_{2}\right\urcorner A\left(x_{1}, y_{1}, x_{2}\left(y_{1}\right), y_{2}\right)
$$

であって, $\left(x_{1}, x_{2}\right)$ が先手の “必勝法”である。だから 有限回が終る game は先手の後手に必ず必勝法があると いうのが排中律の意味である。また，もちろん，変数の 変域が自然数の全体 $の$ のうに整列していれば選択公理 は自明となるであろら。

また，必勝法が “ある”ということは“具体的”に示 すことができるというのと異なることは日常しばしば体 験するところであろら。

少し話は変るが，このよらな “存在”と“具体”の例 は Eularによるといら Fermat 数の因数分解にも見られ よう。Fermat は

$$
\begin{aligned}
& 2^{2^{0}}+1=3,2^{2^{1}}+1=5,2^{2^{2}}+1=17, \\
& 2^{2^{3}}+1=257,2^{2^{4}}+1=65537
\end{aligned}
$$

等は素数であることから，この種の数は素数であろらと 予想したわけであるが，実際には

$$
\begin{aligned}
2^{2^{5}}+1= & 641 \cdot 6700417 \\
2^{2^{6}}+1= & 274177 \cdot 67280421310721 \\
2^{2^{7}}+1= & 59649589127497217 \\
& \cdot 5704689200685129054721
\end{aligned}
$$

のような因数分解が得られている。しかし $2^{2^{8}}+1$ は素数 でなく，したがって自明でない約数が“ある”のである が，“具体的”には知られていない。ついでながら

$2^{2^{n}}+1$ の形の数 (Fermat) で素数となるものは $n \leqslant 20$ には存在しないことが知られている訳であるが上の他に は完全に因数分解されたものは知られていない。

さて, 話老もとにもどして, 論理式の束縛記号を無限
にし，可算列の集合 $A$ を考えれば

$$
\exists x_{1} \forall y_{1} \exists x_{2} \forall y_{2} \cdots\left(\left(x_{1} y_{1} x_{2} y_{2} \cdots\right) \in A\right)
$$

の意味を，有限の場合を“まねて”

$$
\text { \# } y_{1} \exists y_{2} \cdots \forall x_{1} \forall x_{2} \cdots\left(\left(x_{1} y_{1}\left(x_{1}\right) x_{2} y_{2}\left(x_{1} x_{2}\right) \cdots\right) \in A\right)
$$
とすのが自然であろう。これらは函数の概念を用いれば 马 $y \forall x((x(1) y(x(1)) x(2) y(x(1) x(2)) \cdots) \in A)$ であって,$x$ は先手の “手”であり,$y$ は後手の “必勝 法”である。

ここにいら, 決定性公理 $\mathrm{AD}$ は各手は自然数, すなわ

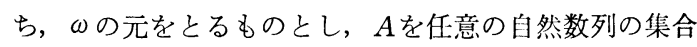
として，排中律に相当する性質，すなわち

“先手または後手に必勝法がある”

\section{こととするのである。}

この公理から得られる結果の一部を記しておくと次の ようである。

(a) 実数の全体に整列順序が入らない

(b) 実数列の countable axiom of choice が成立する。

(c) すべての実数の部分集合は Lebesgue 可測である。

(d) ハ上 $2^{\times 0}$ の濃度は比較不可能である。

(e) $\boldsymbol{N}_{1}$ は measurable な基数である。

例えば(e)から(d)を導いてみる，今 $\boldsymbol{N}_{1}$ 上に可算加法的 な 2 值測度で singleton で 0 となるものが存在したとす る。そしてふ ${ }_{1} \rightarrow 2^{\omega}$ なる 1 対 1 の写像があれば，自然に $2^{\omega}$ 上にも同様な測度が入る。測度が 2 值であるから

$$
A_{n}=\left\{f \in 2^{\omega}: f(n) \neq g(n)\right\}
$$

が測度 0 をもつよらに函数 $g: \omega \rightarrow 2$ を定義することが できる, 可算加法性により，その和

$$
\cup A_{n}=2^{\omega}-\{g\}
$$

は測度 0 であるが，これは singleton $\{g\}$ が測度 1 を有 することになり矛盾である。

また $2^{\omega} \rightarrow \aleph_{1}$ なる 1 対 1 の写像があれば， $2^{\omega}$ は非可 算であるから， $\boldsymbol{1}_{1} \rightarrow 2^{\omega}$ なる 1 対 1 の写像が定められる ことになるので, $\boldsymbol{N}_{1}$ と $2^{\text {N0 }}$ の濃度は比較不可能であっ て，非常に強い意味で連続体仮説が成立しないのであ る。

さて, よく知られた内部 model の方法によって, 決定 性公理 $\mathrm{AD}$ から measurable cardinal の存在 MC および 集合論の公理 ZFC の無矛盾性が導かれる。また measurable cardinal の存在は $2^{\times 0}=\aleph_{1}$ とは独立であり一般連 続体仮説とも無矛盾であるが, 構成可能性の公理 $\mathrm{V}=\mathrm{L}$ とは矛盾することが D. Scott, J. Silver および R. Solovay 等によって知られている。そして, strongly inaccessible cardinal の存在 ST は構成可能性の公理とも矛盾しない ことが知られているので. 無矛盾性が導かれることを… 
で記せば

$$
\mathrm{AD} \cdots \rightarrow \mathrm{MC} \cdots \rightarrow \mathrm{ST}
$$

が成立するが，逆方向は成立しないことが解る。これに 関しても ZF と AD の無矛盾性はとらであろらと思わ れているもの，その証明またはその否定の証明は與味深 いものの一つである。

\section{4. その他}

集合論について逆べながら Boole 代数值の集合論につ いて逆べていないのは，その重要性を考光ても，全く “展望”の意味に反するのであるが，ここでは“無限公 理”の方に話の中心が移ってしまったことを申し訳なく 思っている。

最後に，集合論 ZFC から独立であることが知られる ようになったものの中で興味あると思われる Souslin の 仮説の“その後”について記しておきたい。

これは実数全体の順序集合のような端点のない自己稠 密な連続体, 寸なわちその任意の切断が常に最大元また は最小元を有しその両方ではないとき，次の 2 条件が同 值であろらかというものである。

(1) 叮算な椆密集合がある

(2) 互に素な開区間の集合は高々可算である。 これに関してはもちろん(1)から(2)は導かれるので(2)から (1)が導かれるであろらかといらのが問題であって, 導か れるとするのが Suuslin の仮説 SH である。

これに関しては“木構造”すなわち tree を用いた証述 がなされている。すなわち, 部分順序集合 $(T, \leq)$ は, すべての $p \in T$ に対して集合

$$
\{q \in T: q \leq p\}
$$

が整列集合となるとき tree と呼ばれている。そして， “線型順序”と “木構造” の間には “辞書式順序”を通 じて自然な対応がある。

$$
\text { また，Tの部分集合 } C \text { にいて }
$$

$$
\forall x, y \in C(x \leq y \vee y \leq x)
$$

の時 chain と呼ばれ

$$
\forall x, y \in C(x \leq y \vee y \leq x \rightarrow x=y)
$$

の時 anti-chain と呼ばれる。

さらに tree $T$ について

$$
\{q \in T: q \geq p\}
$$

は線型順序集合でないとき，すべての anti-chain が高々 可算であれば， chain も常に高々可算であるので，この
よらな tree $T$ について

(a) $\forall p \in T\left(\#\{q \in T: q \geq p\}=\aleph_{1}\right)$

(b) すべての anti-chain は可算

なる二性質を有するものを Souslin tree と呼んでいる。 Souslin の仮説 SH は Souslin の tree が存在しないと いうのと同值である。

これに関して次のようなことが知られている。すな

(a) わち構成可能性の公理 $\mathrm{V}=\mathrm{L}$ から Souslin の仮 説の否定が導かれる。

(b) $2^{* 0}=\aleph_{1}$ と SH は ZFCの下で互に独立である。 すなわち

$$
\begin{aligned}
& 2^{\aleph_{0}}=\aleph_{1}, \mathrm{SH} \\
& 2^{\aleph_{0}} \neq \aleph_{1}, \quad 7 \mathrm{SH}
\end{aligned}
$$

のどの組合せも集合論 ZFC と無矛盾であるというので ある。このようにして

連続体仮説と Souslin の仮説

は互に他方からその否定も肯定も導かれないような関係 であることが解ってきたわけである。

これらの結果を通じて集合論の言語体系が今後どのよ らに考えられるようになるか興味深いところである。

\section{文献}

1）竹内外史著「現代集合諭入門」口本評論社

2） P.J. Cohen 著，近藤基告，坂井秀寿，沢口昭聿訳 「連続体仮説」東京図書

3）前原昭二著「数学基礎論入門」基数数学シリーズ 26 ，朝倉書店

4）難波完爾著「集合論」サイエンス社

5) K. Gödel, The concistency of the continuum hypothesis, Princeton University Rress. Princeton, N.J., 1940

6) P.J. Cohen, Set theory and the continuum hypothesis, Benjamin, 1966

7) G. Takeuti, W. Zaring, Axiomatic set theory, Springer-Verlag, GMT 101973

8) J.R. Shoenfield, Mathematical logic, AddisonWesley, 1967

9) T.J. Jech, The axiom of choice, North-Holland, 1973

10. T.J. Jech, Set theory, Academic Press, 1978 